\title{
Transition Measurement and Prediction on a Generic High-Lift Swept Wing
}

\author{
F.Moens ${ }^{*}$ \\ Applied Aerodynamics Department (DAAP) \\ ONERA-Châtillon \\ PO Box 72, F-92322 Châtillon Cedex \\ Frederic.Moens@onera.fr \\ and \\ J.Perraud ${ }^{\dagger}$, A.Séraudie ${ }^{\ddagger}$ and R.Houdeville ${ }^{\#}$ \\ Department for Aerodynamics and Energetics Model (DMAE) \\ ONERA-Toulouse \\ PO Box 4025, F-31055 Toulouse Cedex
}

\begin{abstract}
This paper presents experimental and numerical studies on the effect of the Reynolds number on transition location for a simplified multi-element wing. The main phases of the test preparation and the main results of the data analysis carried out within the EUROLIFT EC funded programme are given in a first part. In the second part of the paper, recent assessments of the ONERA elsA CFD software where transition is computed during the Navier-Stokes calculation are presented for both the effect of change in $\alpha$ at a given Reynolds number and the change in Reynolds number at constant incidence.
\end{abstract}

Keywords: High-lift, transition, IR, hot films, CFD.

\section{Introduction}

The aircraft performance in high-lift conditions are directly related to the maximum lift. However, most of the high-lift tests are carried out at sub-scale condition and aircraft performance are then derived by extrapolation to flight Reynolds number. Taking into account this Reynolds number effect early in the design process would allow significant cost reduction for aircraft manufacturers. But such extrapolation is only possible if the transition process is well understood in both wind tunnel and flight conditions. Some so-called "adverse Reynolds number effects" often occur when comparing extrapolation from the wind tunnel to the flight test results. For transport aircraft configurations, most of these effects are due to a change in the transition process [1], and some trends, as schemed in figure 1, can be observed. This effect can be taken into account in the design phase directly by carrying out tests in a cryogenic pressurized wind tunnel, such as ETW. Another solution is to consider "sufficiently" high Reynolds numbers in low-speed pressurized wind tunnels and to transpose to flight conditions taking into account the effects of transition changes, which could be simulated during the test campaign. Anyway, the knowledge of the transition process and its change with Reynolds number or sweep angle is necessary for the understanding of scale effects on a high-lift wing. Therefore, within the EUROLIFT EC funded programme [2], it was decided to consider specific wind tunnel test campaign dedicated to the study of the transition process on a generic high-lift configuration with the objective to provide

\footnotetext{
* DAAP Civil Aircraft Unit, ONERA Châtillon

$\dagger$ DMAE Transition and Instability Unit, ONERA Toulouse

\$ DMAE Transition and Instability Unit, ONERA Toulouse

\# DMAE Turbulence, Modeling, Forecast Unit, ONERA Toulouse
}

\author{
: Frederic.Moens@onera.fr \\ : Jean.Perraud@onecert.fr \\ : Alain.Seraudie@onecert.fr \\ : Robert.Houdeville@onecert.fr
}


a detailed database for the transition prediction tool developers, and for CFD assessment [3]. This database is now used for the validation of the results from CFD design tools where transition is computed, and not imposed a-priori.

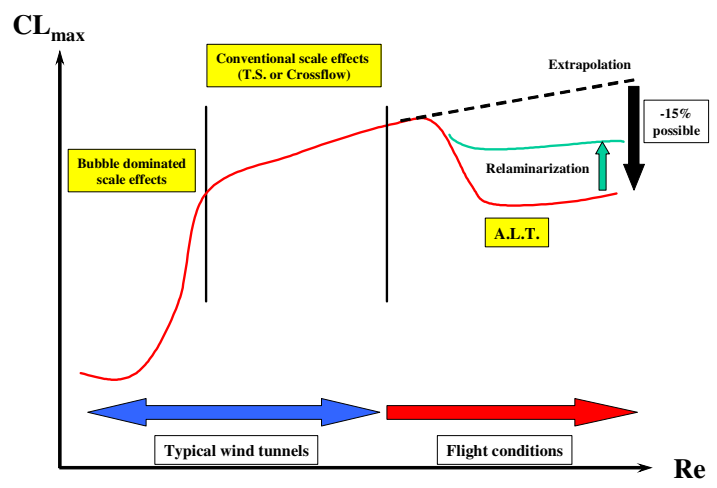

Figure 1: Scheme of an "adverse Reynolds number effect" on $\mathrm{CL}_{\max }$

\section{First phase: test campaign}

\section{Model and test setup}

The model used is the ONERA AFV model, which is a rectangular untwisted wing, based on a three-element airfoil configuration. The reference 2D shape of the wing is the RA16SC1 profile, with a reference chord of $0.5 \mathrm{~m}$ perpendicular to the leading edge, a slat leading edge $\left(\delta_{\text {slat }}=30^{\circ}\right)$ and a flap $\left(\delta_{\text {flap }}=20^{\circ}\right)$. Tests carried out for the EUROLIFT programme considered two sweep angles, $\varphi=30^{\circ}$ and $\varphi=40^{\circ}$. The results presented here are based on the case $\varphi=40^{\circ}$ only, and in that case, the wing span is $2 \mathrm{~m}$ (from tunnel floor to wing tip), and the different pressure rows and fairings are parallel to the floor. The AFV model is equipped with 8 rows of 93 pressure taps each (total $=744$ ) distributed over the 3 elements. The pressure taps of the model are connected to PSI modules which allow fast recording to be carried out, in parallel to the balance measurement. A wall balance measured forces and moments during the tests, and accelerometers controlled the vibration level. Transition detection was performed using infrared thermography and hot films distributed along a chordwise section of the 3 elements (figure 2).
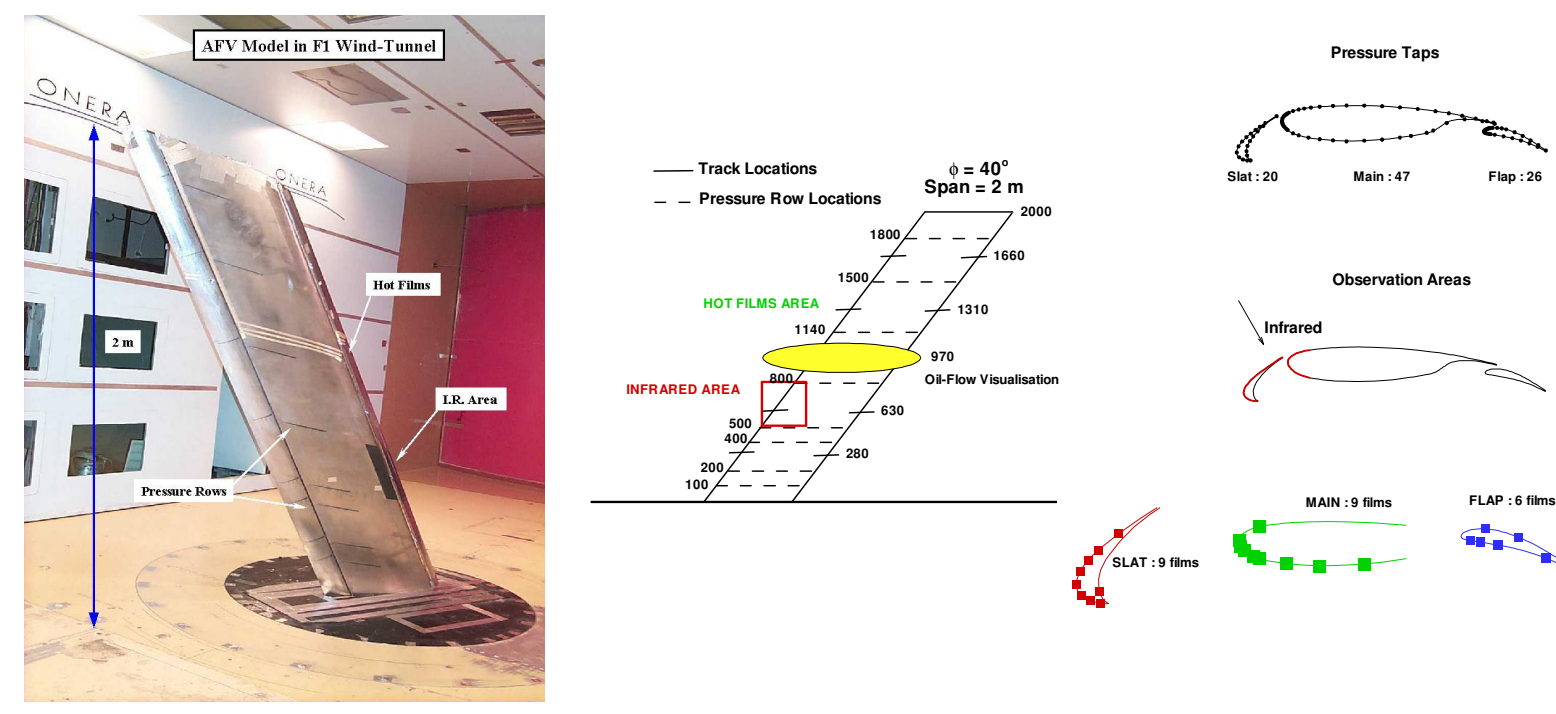

Figure 2: Equipment of the AFV model for EUROLIFT test campaign. 
A region of the slat upper side and of the wing leading edge was covered with a thin layer of specific black paint ensuring a large enough emissivity coefficient. Twenty four Dantec hot films were distributed on the 3 parts of the model on the slat (9), the wing (9) and the flap (6). They were glued directly on the metallic wing and electrical connections were realized with thin copper strips. The analysis of the hot films data considered the RMS level, recorded during a continuous polar, and the signal evolution obtained during the infrared measurements.

\section{Preliminary computations}

In order to select the right configurations for the tests and to optimise the location of the hot films, some pre-test 3D Navier-Stokes computations, carried out by ONERA within the Garteur AD(AG36) Action Group [4], were used. As a first result, a very good correlation on CP distribution between previous experiments and computations was observed at the different measuring stations along the span (figure 3 ). The computed pressure field can therefore be used for the transition location evaluation with boundary layer codes. As the experiments were dedicated to transition study, it was necessary to verify first if leading edge contamination occurs or not. Because the model is fixed directly on the floor, such contamination is likely to occur for certain conditions.

This problem has been analysed through the evolution of the Reynolds number: $\bar{R}=\frac{W_{e}}{\sqrt{v \frac{\partial U_{e}}{\partial X}}}$. According to

an empirical criterion [5], contamination occurs for values above 250. Results obtained (figure 4) show that for the sweep angle $\varphi=40^{\circ}$, the main wing will be contaminated in most wind tunnel conditions. Contamination is expected to appear on the slat at about $\operatorname{Re}=4.510^{6}$, and the flap should not be contaminated.
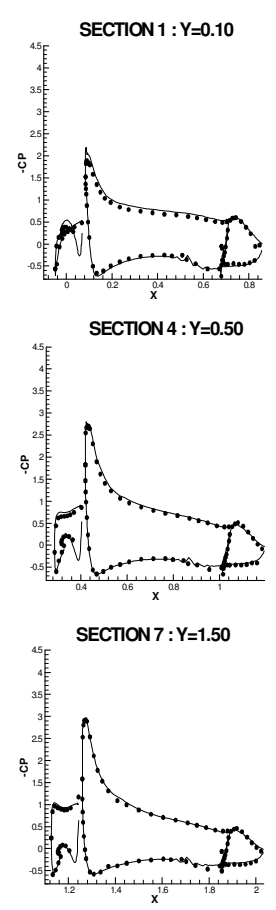
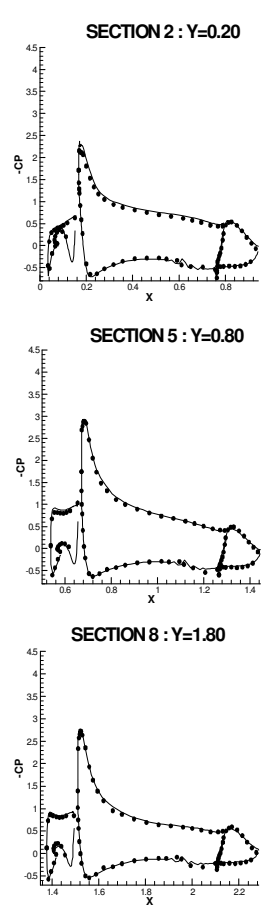

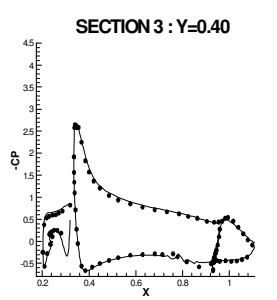

SECTION $6: Y=1.14$
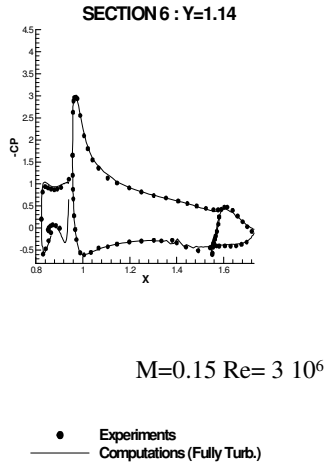

Figure 3: Pressure distributions on the AFV wing - Comparison CFD results with previous experiments $\left(\mathrm{M}=0.15, \mathrm{Re}=3.310^{6}\right.$, $\alpha=10.93^{\circ}$ ).
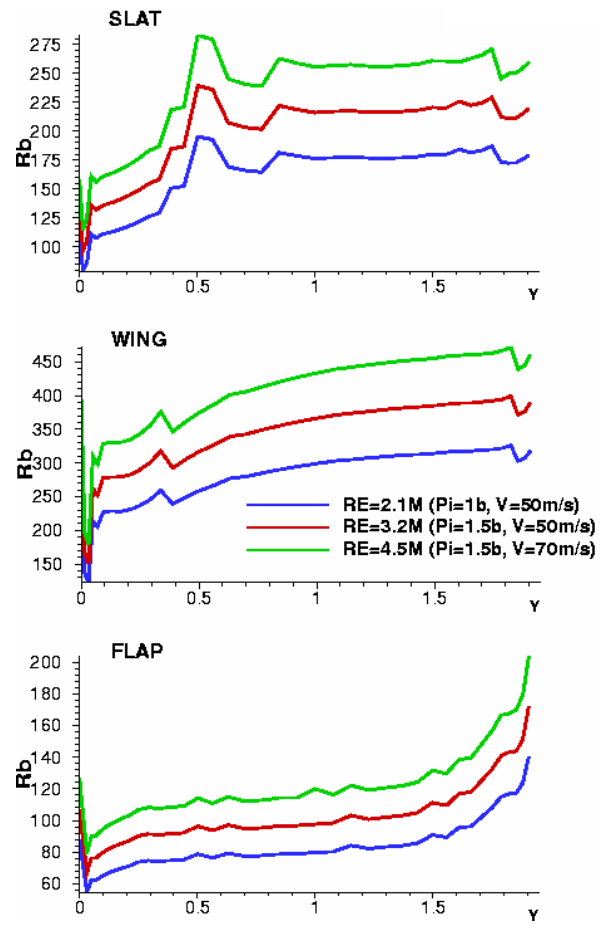

Figure 4: Contamination of the AFV wing based on CFD results $\left(\varphi=40^{\circ}, \alpha=10.93^{\circ}\right)$.

During EUROLIFT project, the preliminary transition work was performed by several partners (FOI, DassaultAviation, Airbus-Deutschland and ONERA), and the location of sensors were defined as presented in figure 2. More details can be found in [6]. 


\section{Test campaign}

The test was performed in the ONERA-F1 low speed pressurised wind tunnel located at the ONERA centre of 'Le Fauga Mauzac', at the end of year 2000. Based on the preliminary computations, it was agreed by the different partners to investigate particularly the effect of Reynolds number change at a constant Mach number of 0.20. The following Reynolds numbers were considered: $\mathrm{Re}=2.810^{6}, 4.510^{6}, 5.910^{6}, 7.510^{6}$ and $10.710^{6}$, based on a reference chord of $c=0.657 \mathrm{~m}$ for $\varphi=40^{\circ}$. In addition, the same test condition as used in Garteur AG36 has been selected. For the measurements of forces and pressures, two sets of data were obtained depending on the acquisition means, and it was checked that these two types of acquisition give the same results:

1) Continuous polar: the angle of attack increases from $-5^{\circ}$ up to $\mathrm{CL}_{\max }$ and beyond, at a continuous speed of $0.2^{\%}$ s. There is one $\mathrm{CP}$ record per second during this phase. Then $\alpha$ decreases up to about $10^{\circ}$, to catch the hysteresis effects, but with no $\mathrm{CP}$ record.

2) Stable points: this is for the detailed transition measurements, and about ten CP records are done, in order to check the flow stability. There are about 7 stable points recorded per aerodynamic condition. In order to get a good contrast on the infrared images, a thermal shift of about $2^{\circ} \mathrm{C}$ was imposed during the data acquisition.

\section{Second phase: data analysis}

A detailed analysis of the results obtained in this test campaign can be found in [6-7]. Here, only main results related to the reference case, $\varphi=40^{\circ}$ and $\delta_{\text {Flap }}=20^{\circ}$, are presented.

\section{Experimental results}

The first important observation to point out is that for the flow condition $M=0.20, \operatorname{Re}=7.510^{6}$, leading-edge contamination occurs on the three elements. In that case, CFD results obtained under the assumption of a fully turbulent flow can be directly compared to these experimental results, which makes a database for turbulence model evaluation. Then it was noted that there was no major Reynolds number effect observed on the measured $\mathrm{CP}$ distribution on the different elements at a given section (figure 5).

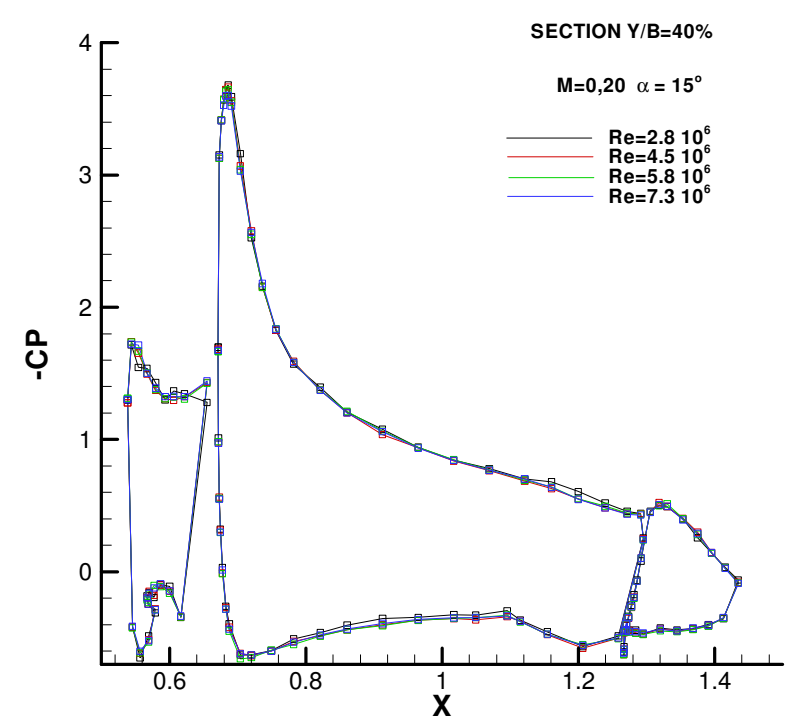

Figure 5: Experimental Reynolds number effect on the CP distributions at mid-span $\left(\alpha=15^{\circ}\right)$.

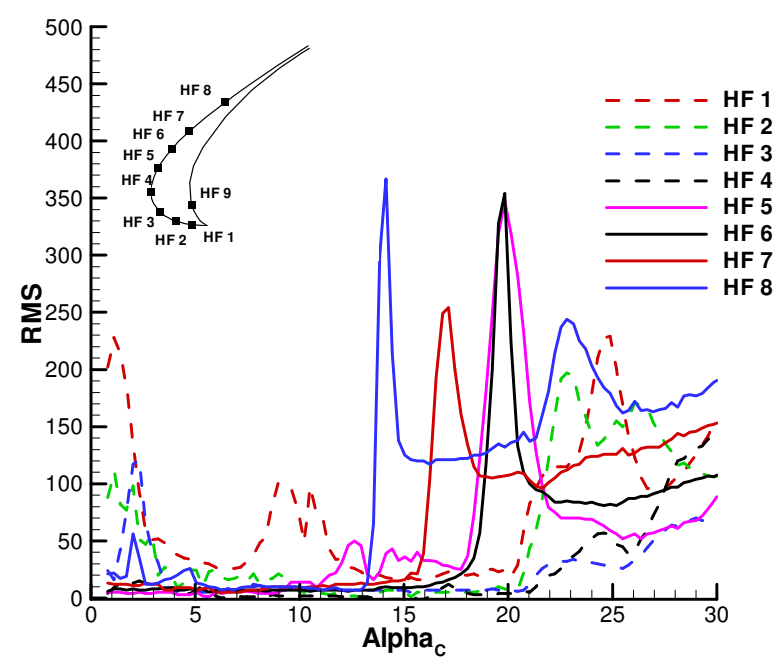

Figure 6: Hot films on the slat - Evolution of the RMS value with $\alpha\left(\operatorname{Re}=2.810^{6}\right)$. 


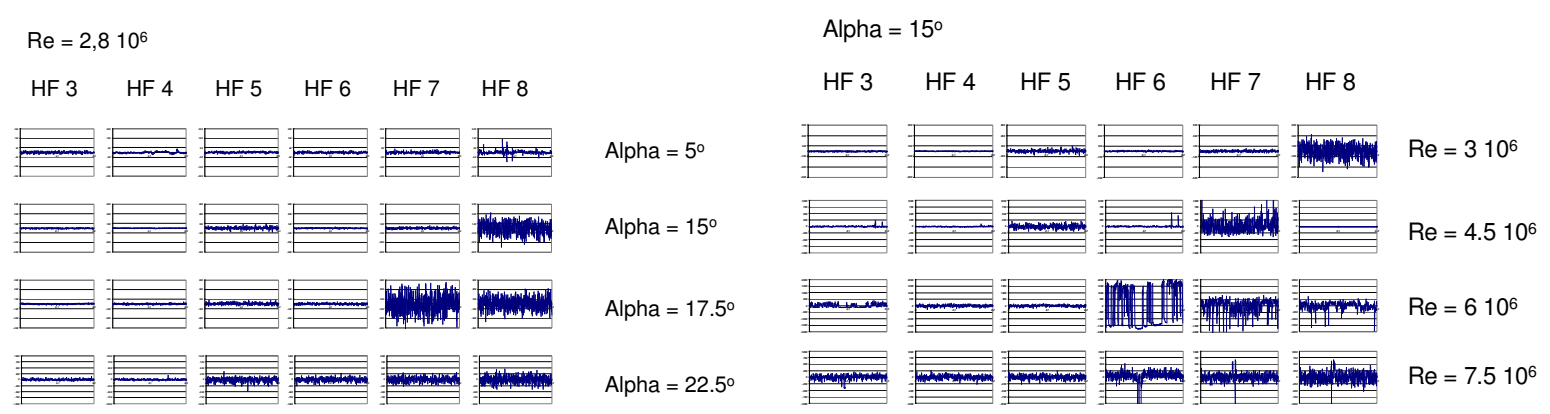

Figure 7: Hot film on the slat - Temporal signal Effect of angle of attack variation at $\operatorname{Re}=2.810^{6}$.

Figure 8: Hot film on the slat - Temporal signal Reynolds number effect at $\alpha=15^{\circ}$.

For the reference configuration, the analysis of the experimental results related to transition focuses on the slat. The effect of a change in the angle of attack are obviously significant for this element, whereas the flow on the flap is nearly unaffected by the incidence. For $\operatorname{Re}=2.810^{6}$, experimental results on the slat hot films clearly show the movement of the transition from trailing edge to the leading edge when $\alpha$ increases, as well on RMS values (figure 6) and on temporal signal (figure 7).

For $\alpha=15^{\circ}$, the increase in Reynolds number shows the change in transition location, up to contamination for $\mathrm{Re}=7.510^{6}$ (figure 8). Infrared pictures, although not located at the same wing section, confirm these observations (figure 9) and give complementary information. For instance, at $\alpha=5^{\circ}$, white laminar and grey turbulent regions are visible, but the delimitation is difficult to define on the picture. At $\alpha=20^{\circ}$, the frontier between white and grey areas is clearly visible. These different evolutions are related to different transition processes (crossflow and short bubble).

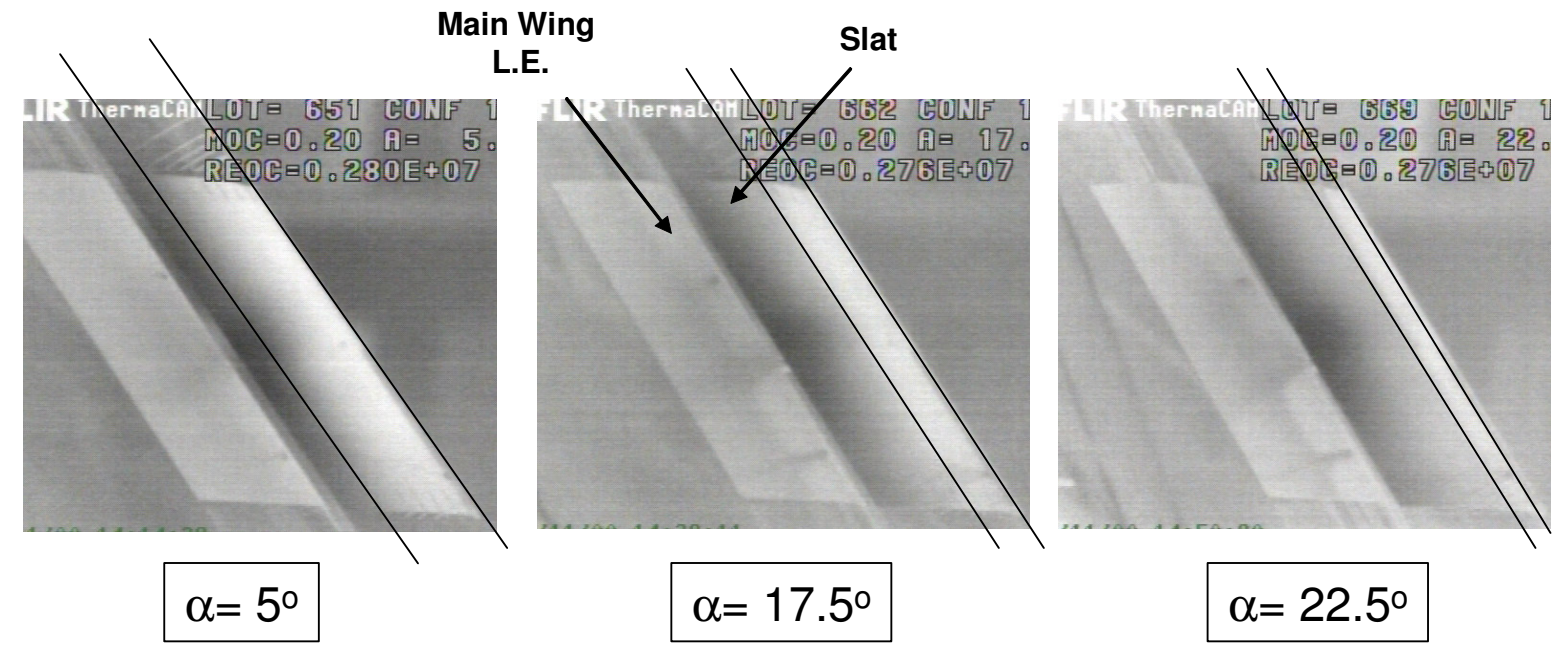

Figure 9 - Infrared images on the slat - Angle of attack effect at $\mathrm{Re}=2.810^{6}$.

\section{Fully turbulent RANS computations}

A structured multi-block mesh of $3.16 \times 10^{6}$ nodes, containing 40 domains, was generated for the reference configuration $\left(\varphi=40^{\circ}, \delta_{\text {Slat }}=30^{\circ}, \delta_{\text {Flap }}=20^{\circ}\right)$. The preliminary calculations used for test preparations showed that a $\mathrm{y}^{+}$value below 1 was ensured. Within the EUROLIFT project, the objective of these computations was to provide an accurate pressure distribution for boundary layer calculation inputs. In addition, a first validation of turbulence models can be carried out, thanks to the "fully turbulent" experimental data for $\operatorname{Re}=7.510^{6}$. 


\section{Numerical method used}

The computations were carried out using the ONERA elsA software [8-9]. They were obtained using a uncoupled approach between the RANS system and the turbulence model transport equations. For the explicit scheme, a 4-step Runge-Kutta space centred type scheme, as proposed by Jameson, is used for the conservative variables. A fourth order linear dissipation is generally used, with added second order dissipation terms for treatment of flow discontinuities. For the implicit stage, a LUssor scheme is associated with an Euler backward time integration scheme. For the turbulent variables, the Roe numerical scheme is used. Different multi-grid techniques are available for convergence acceleration ( $\mathrm{V}$ or $\mathrm{W}$ cycles), as well as low-speed preconditioning.

\section{Effect of turbulence models}

Among the different turbulence models available in elsA, the following ones have been evaluated on the AFV configuration at $\mathrm{M}=0.20$ and $\mathrm{Re}=7.510^{6}$ for 3 angles of attack $\left(\alpha=20^{\circ}, 30^{\circ}\right.$ and $\left.34^{\circ}\right)$ : Spalart-Allmaras (SA) [10], Wilcox k- $\omega[11]$ and Smith's k-1 [12]. Whatever the model considered, the quality of the computed pressure field can be considered good before maximum lift. Looking more into details, it appears that the $k-\omega$ model overestimates the pressure peak on the slat and main wing (figure 10), and does not reproduce the correct slope $\mathrm{dCL} / \mathrm{d} \alpha$ (figure 11). Results obtained with the SA and k-l models are very close except at maximum lift, where $\mathrm{CL}_{\max }$ is computed at a lower $\alpha$ than measured for the S.A. model.

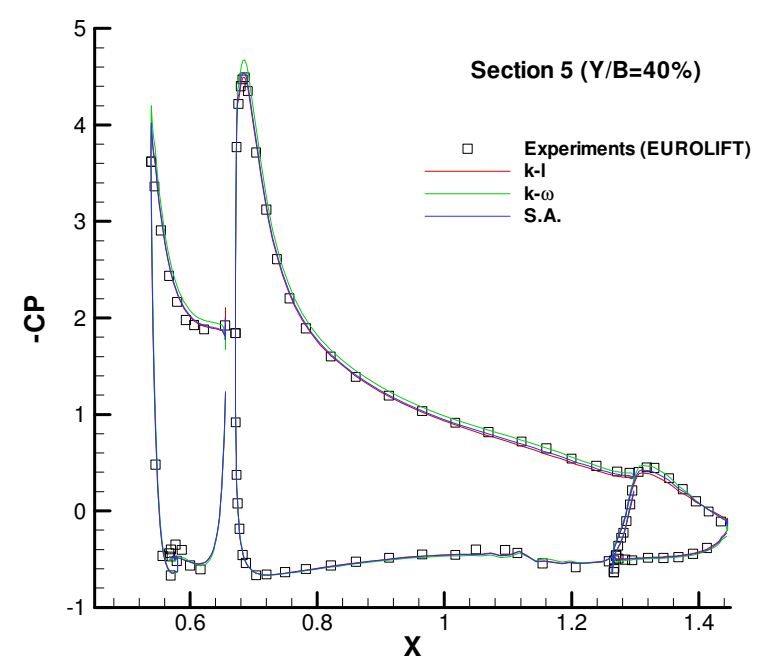

Figure 10: Effect of turbulence model - CP distributions at mid-span $\left(\mathrm{M}=0.20, \mathrm{Re}=7.510^{6}\right.$, $\alpha=20^{\circ}$ )

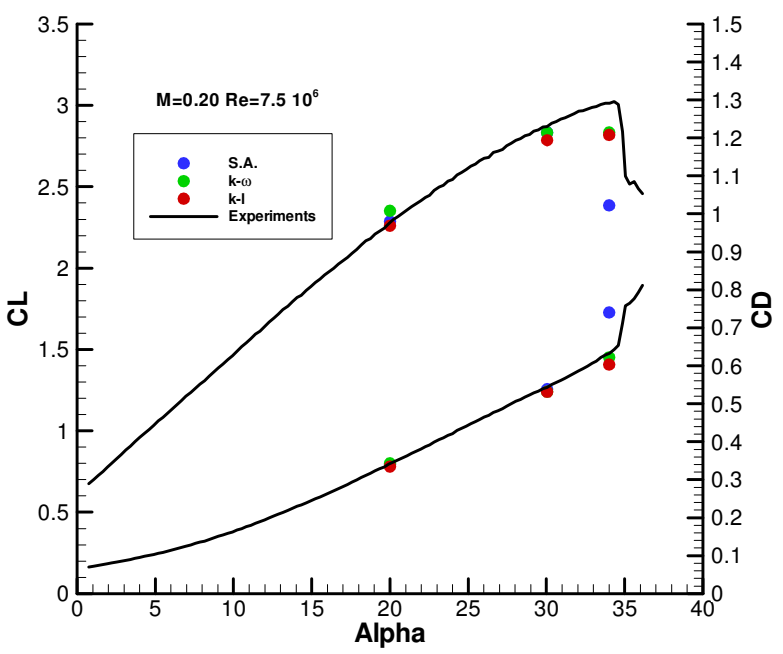

Figure 11: Effect of turbulence model - Force coefficients $\left(\mathrm{M}=0.20, \mathrm{Re}=7.510^{6}\right)$

For an accurate estimation of the pressure field with boundary layer codes, Navier-Stokes results obtained with both S.A. and k-1 models are therefore quite satisfactory. In addition, based on the observation made on experimental $\mathrm{Cp}$ distributions, these numerical pressure fields obtained for $\operatorname{Re}=7.510^{6}$ can be used for the transition prediction analysis at different Reynolds numbers, as there is no significant effect of the change in Reynolds number of experimental pressure coefficients (figure 5).

The 10 angles of attack considered for detailed transition measurements have been computed and results provided to partners involved in the transition prediction task in EUROLIFT. It can be seen that the agreement on CP distribution at mid-span is good on the complete range of $\alpha$ (figures 12,13). 


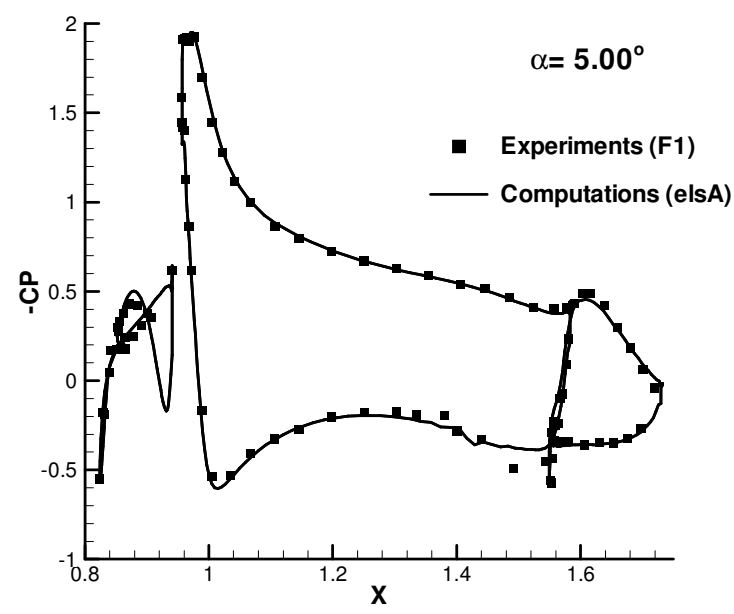

Figure 12: Pressure distributions at mid span Comparison with experiment at $\alpha=5^{\circ}$.

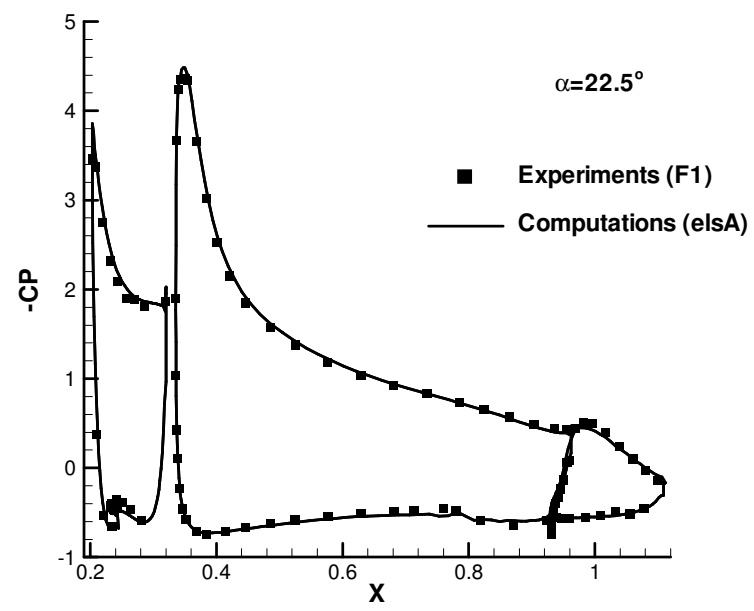

Figure 13: Pressure distributions at mid span Comparison with experiment at $\alpha=22.5^{\circ}$.

\section{Transition prediction}

The transition prediction work in EUROLIFT project involved several partners: Airbus-Deutschland, AirbusSpain, CIRA (Italy) and FOI (Sweden) together with ONERA. A complete description of the methods used can be found in [7]. Here, only main results from ONERA and FOI are presented. At the start of the project, it was shown that the viscous wall regions computed by a RANS solver could not reasonably provide the precision required for stability computations and transition prediction, due to the necessary artificial viscosity used, allowing a fast convergence and numerical stability. It was thus agreed to use boundary layer codes under the assumption of infinite swept wing (2.5D flow), using the mean flow pressure distribution provided by turbulent flow computations. For the AFV model, this assumption is verified in the mid span of the wing (see figure 3 for instance).

In a first exercise, the prediction transition location on a single element swept wing using exact stability theory or database method, which give nearly the same $\mathrm{N}$-factor (figure 14). Then, the results obtained on the multi-element AFV wing have been analysed in the course of the EUROLIFT project.

Results obtained on the slat upper surface at $\mathrm{Re}=2.8$ $10^{6}$ are presented in figure 15 , and compared to the transition location obtained from the analysis of hot films signals and infrared pictures.

At low angles of attack, the transition is located downstream, nearly at the trailing edge $(X=0.12 \mathrm{~m})$. This is due to the negative pressure gradient on this element (see figure 12 for instance). Then, as $\alpha$ increases from $10^{\circ}$ to $20^{\circ}$, the transition moves upstream, separation bubbles appearing at $\alpha=17.5^{\circ}$. From $\alpha=20^{\circ}$ to $22.5^{\circ}$, the transition location remains nearly unchanged, and is located in the strong pressure recovery gradient on the slat.
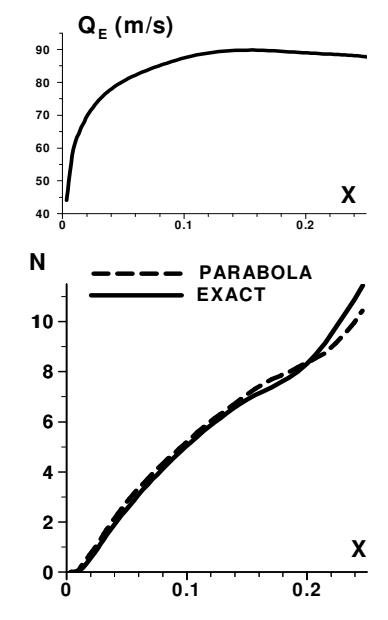

Envelope curves,
swept ONERA D profile ( $\varphi=30^{\circ}$, Mach 0.25$)$

Figure 14: Validation of the database method on a simple three-dimensional flow $\left(\operatorname{Re}=1.7510^{6}, \alpha=-6^{\circ}\right.$ ) 


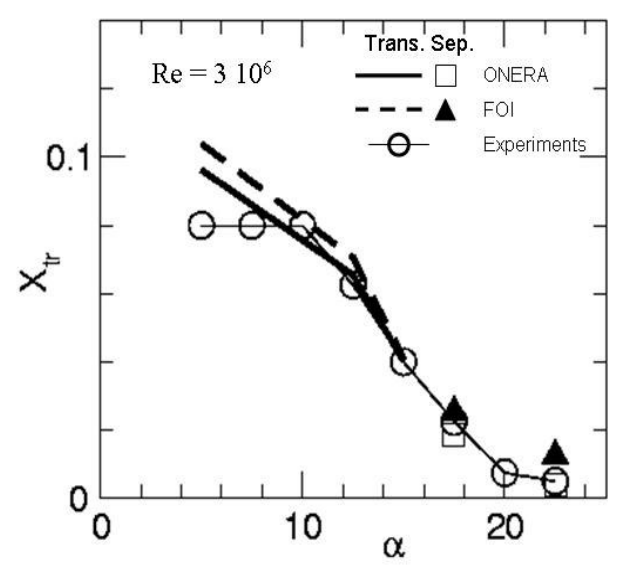

Figure 15: Transition location on the slat upper surface $\left(\operatorname{Re}=2.810^{6}\right)$. Comparison between prediction tools and measurements.

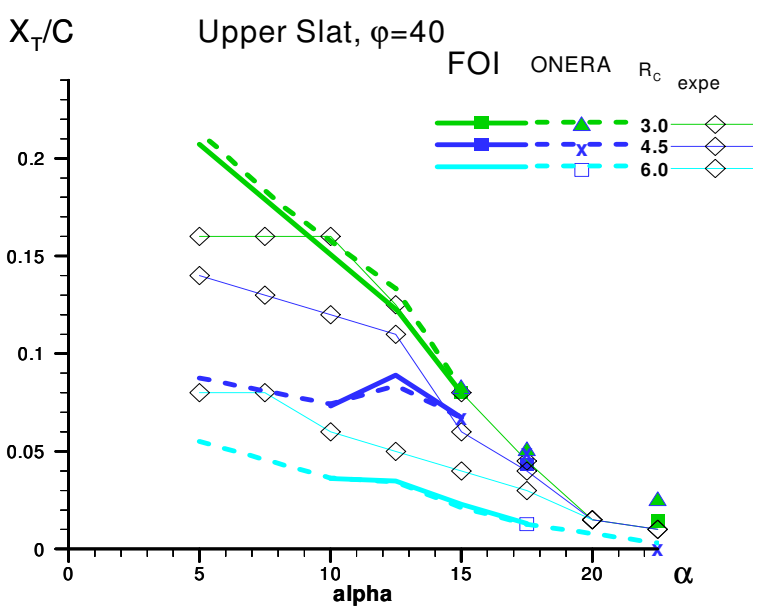

Figure 16: Transition on the slat upper surface - Reynolds number effect - Comparison prediction/measurements $(\mathrm{C}=0.50 \mathrm{~m})$.

Changing the Reynolds number leads to the results presented in figure 16. The predictions are seen to match well with the experiments. Boundary layer codes also indicate which transition type is active first: transition is of the Tollmien-Schlichting (TS) kind at $\alpha=5^{\circ}$, then at $\alpha=10^{\circ}$ both TS and crossflow instabilities are comparable. Between $10^{\circ}$ and $15^{\circ}$, transition is of crossflow type, and separation occurs first for $\alpha$ above $15^{\circ}$.

\section{Third phase: Navier-Stokes calculation with computed transition}

\section{Implementation in elsA}

There are different ways to take transition into account. All of them rely on the concept of effective viscosity $\mu_{\text {eff }}=\mu+\Gamma \mu_{t}$, where $\Gamma$ is the intermittency function. A first method is to impose a laminar region, but it requires a a-priori the knowledge of the transition location. It is generally done by coupled boundary layer calculation carried out on the computed pressure field during the convergence process of the RANS computation.

A second method is to compute the transition location during the RANS computation. In that case, the compatibility between the flow computed and the transition location is always ensured, but this implies a frequent calculation of the transition. Hence, transition prediction tools implemented in a RANS solver should be fast. In addition, computing the transition location can be carried out using either local or non local criterion. A criterion is local if it only uses any information coming from the cell belonging to the normal resulting from the interface wall where the criterion is applied. This excludes the concept of progressive transition. For nonlocal criteria, based on the concept of transition line calculation, some information about the "history" of the boundary layer state are used: the flow starts being laminar, then enters the intermittency region (entry criterion), then leaves it (exit criterion) before entering the turbulent domain.

The computations presented hereafter are based on the use of non-local criteria. The 3D database method is not implemented yet in the ONERA elsA software. Transition is computed using a combination of different criteria, and is imposed when the first one is activated. The Arnal-Habiballah-Delcourt criterion [13] is used for T.S in combination with the Gleizes criterion [14] for 2D laminar separation bubbles onset. For crossflow, the C1 criterion is used [15]. It should be noted also that at present, there is no intermittency region taken into account and $\Gamma$ grows directly from 0 to 1 in one cell. Computations started with a fully turbulent calculation. Then, the computation of transition location was activated, up to convergence. The criteria are evaluated every 20 cycles. In this paper, only the transition process of the slat is analysed. However, the transition on the flap is also considered during the computations. For the main wing, turbulent flow is imposed as leading-edge contamination occurred in the experiments. 


\section{Effect of a variation of the incidence at $R e=2.810^{6}$}

The figure 17 presents the evolution of the computed transition area on the slat with $\alpha$ through the value of the intermittency factor. Red colour corresponds to laminar state $(\Gamma=0)$ and blue to turbulent flow $(\Gamma=1)$.

Similar trends to the observations made on infrared images (figure 9) are obtained by the computations. For $\alpha=5^{\circ}$, a laminar flow on the complete upper surface is found, for $\alpha=15^{\circ}$ and $17.5^{\circ}$, the upward displacement of transition is visible, and for $\alpha=22.5^{\circ}$, a clear transition line is observed.

Results obtained are also in accordance with the analysis made in EUROLIFT project, with transition due to T.S. or crossflow between $10^{\circ}$ and $20^{\circ}$, the latter being preponderant at high angle of attack in the hot film region.

The comparison of the computed transition location during the elsA calculations with the experimental results at the hot film measuring wing section (from figures 6-7) is given in figure 18. Very good agreement is observed for low $\left(\alpha=5^{\circ}\right)$ and high $\left(\alpha=22.5^{\circ}\right)$ angles of attack.
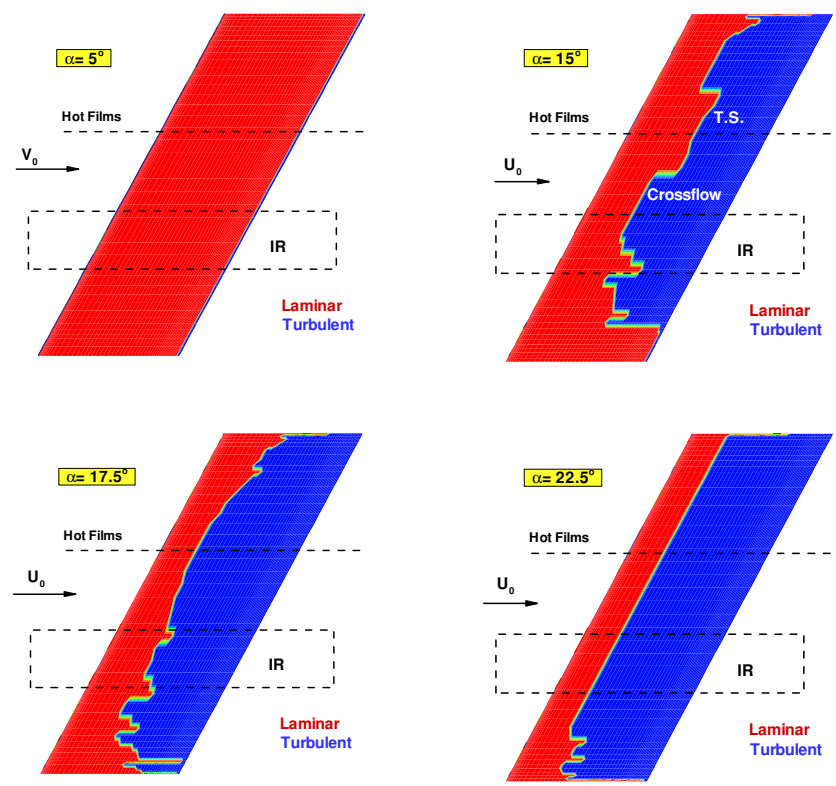

For intermediate incidences $\left(\alpha=15^{\circ}\right.$ and $\left.17.5^{\circ}\right)$, the agreement is slightly reduced. These correspond to the significant displacement of the transition location (figure 15).

In addition, transition locations due to crossflow and T.S. are close from each other, and it can be seen in figure 17 that thee-dimensional effects on the transition area are significant for these incidences, and maybe the use of $3 \mathrm{D}$ criteria should be more appropriate.

For $\alpha=22.5^{\circ}$, the transition is found at its proper location. However, the analysis carried out on turbulent pressure distribution with boundary layer codes using 2.5D criteria found a laminar separation bubble (figure 16). For the NavierStokes computations carried out using criteria, there is no clear separation computed, although the laminar separation bubble criterion is taken into account. Figure 19 compares the computed skin friction coefficient on the slat for fully turbulent and transitional computations for $\alpha=22.5^{\circ}$. It can be noted that no reverse flow is detected, although the skin friction value is low.

This difference may be due, either to the procedure retained for the data analysis, or to the two-dimensionality of the criterion used.

Figure 17: Computed transition area on the slat for $\alpha=5^{\circ}$, $15^{\circ}, 17.5^{\circ}$ and $22.5^{\circ}\left(\mathrm{M}=0.20, \mathrm{Re}=2.810^{6}\right)$.
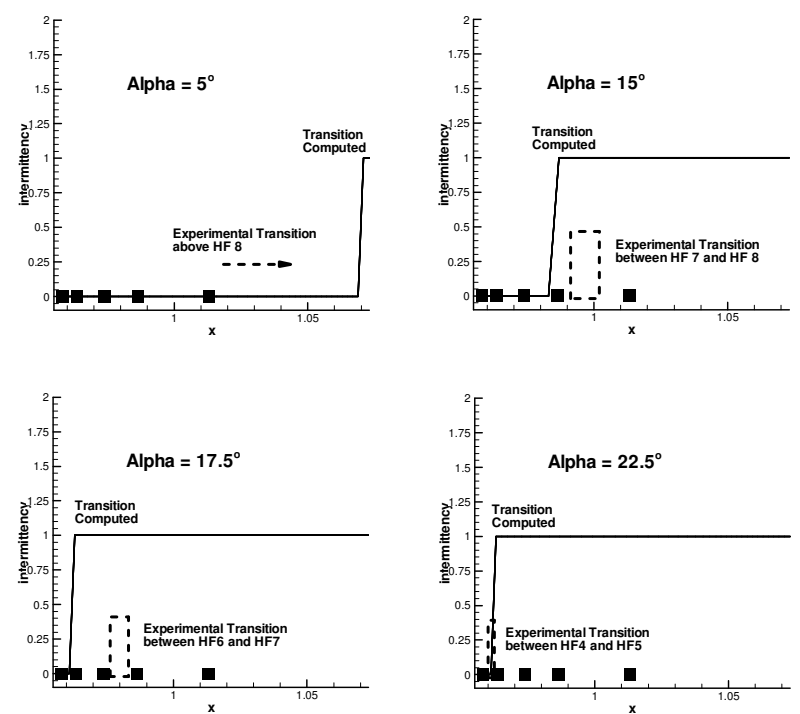

Figure 18: Variation of the incidence at $\operatorname{Re}=2.810^{6}$.

Comparison of computed transition location with experimental results at the hot film measuring section.

Finally, some computations were carried out up to and beyond maximum lift (figure 20). It can be seen that taking into account transition during the computations has no significant effects in the linear part of the $\operatorname{CL}(\alpha)$ and $\mathrm{CD}(\alpha)$ curves, but has a visible impact on performance close to maximum lift. A better agreement is observed in this region when transition is taken into account, although some discrepancies remain. 


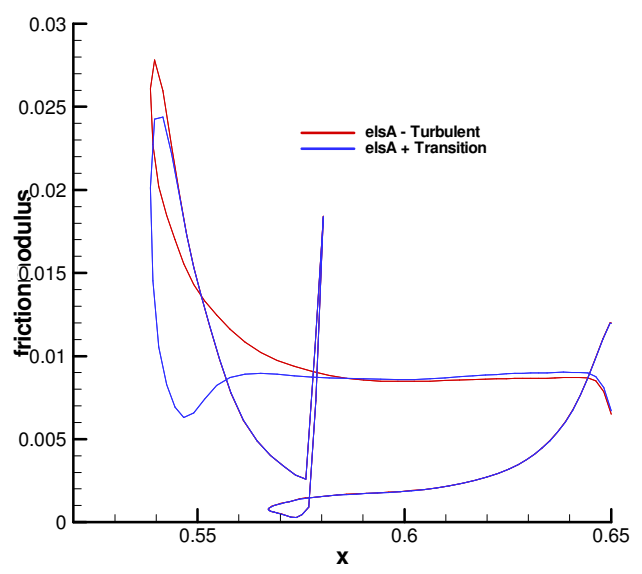

Figure 19: Skin friction coefficient on the slat at the hot film location $\alpha=22.5^{\circ}$. Comparison between fully turbulent calculations and with transition criteria taken into account

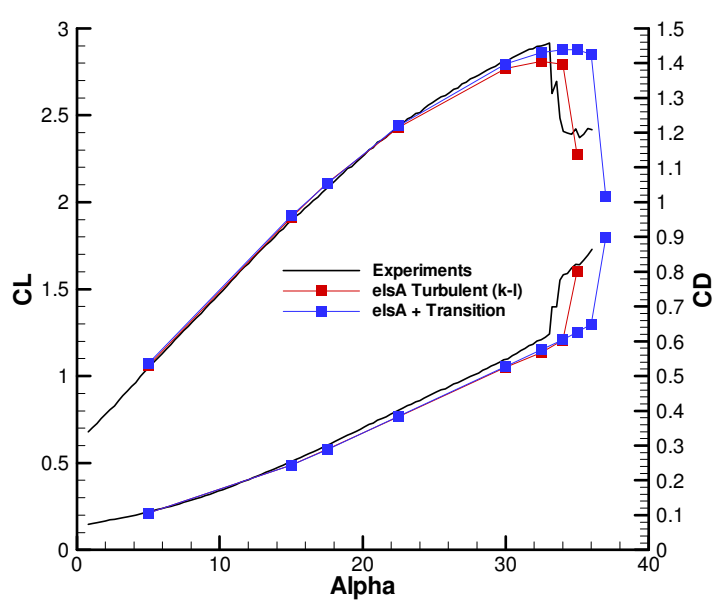

Figure 20: $\mathrm{CL}(\alpha)$ and $\mathrm{CD}(\alpha)$ curves $(\mathrm{M}=0.20, \mathrm{Re}=2.8$ $\left.10^{6}\right)$. Effect of transition taken into account in the elsA computations (k-l model) - Comparison with experiments.

The small effect of transition on CL in the linear part has already be noted in the preliminary phase, and observed in the experiments (figure 5). This implies that the lift induced drag and the pressure drag coefficients, which are the preponderant ones for high-lift configurations, remain nearly unchanged in that case. This explains the small sensitivity of drag coefficient to the transition in that case.

\section{Reynolds number effect at $\alpha=15^{\circ}$}

The final assessment for the transition prediction is about the effect of the change in Reynolds number. The problem for this exercise was to choose an angle of attack where transition changes were observed experimentally, but not due to leading-edge contamination. The evolution of the experimental $\bar{R}$ on the slat with $\alpha$ and the Reynolds number is presented in figure 21 .

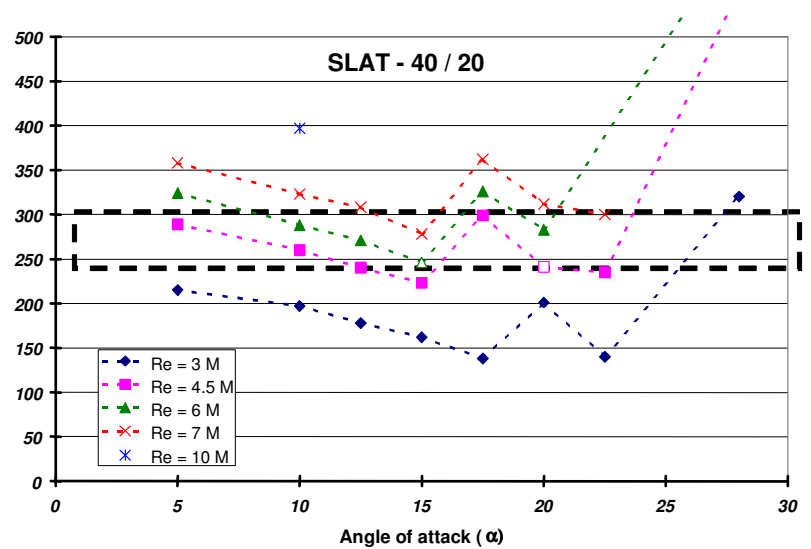

Figure 21: Analysis of leading-edge contamination on the slat.

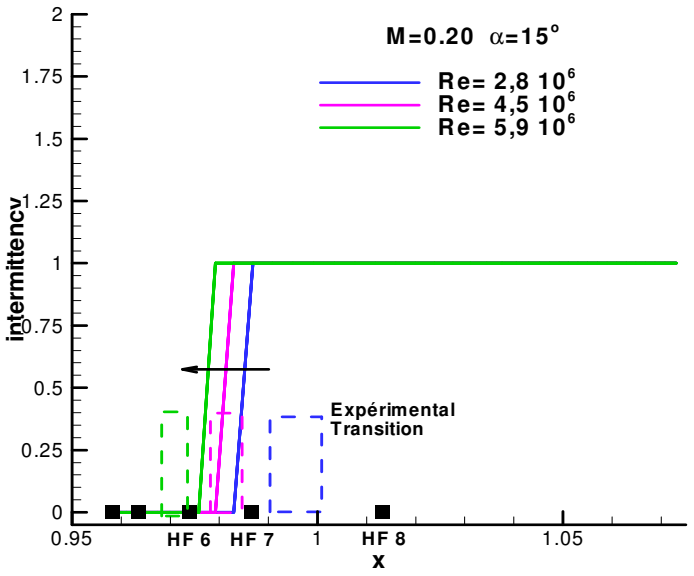

Figure 22: Reynolds number effect. Comparison of computed transition location with experimental results at the hot film measuring section.

It can be seen that for most of the cases for $\operatorname{Re} \geq 4.510^{6}, \bar{R}$ is close to its critical value, particularly for angles of attack below $12.5^{\circ}$, but hot film signals seem to correspond to a turbulent flow for $\mathrm{Re}=7.510^{6}$ only (figure 8). In 
order to have relevant experimental data for comparisons, the effect of the Reynolds number has been studied at $\alpha=15^{\circ}$.

The comparison of computed transition location at the hot film wing section with experimental results, from the analysis of the hot film signals, is presented in figure 22. The upward displacement of the transition location when Reynolds number increases is well reproduced by the simulation, at about the same amplitude from $\operatorname{Re}=4.510^{6}$.

Based on these encouraging results, the analysis of an experimental adverse Reynolds number effect observed on a low speed clean wing configuration at ETW during the EUROLIFT project [16] will be analysed numerically in the follow on EC project EUROLIFT II, which started in 2004, using the elsA software with the existing transition prediction tools. In addition, improved transition prediction tools will be implemented in the elsA software in a near future, in order to deal with 3D laminar separation bubbles, leading-edge contamination criteria, relaminarisation criterion and a 3D (or $2.5 \mathrm{D}$ ) criterion for transition.

\section{Conclusions}

Thanks to the EUROLIFT project, a detailed experimental database has been built up in order to study the effect of the Reynolds number on transition location in high-lift cases. For the preparation of the tests, a first integrating study was carried out. The selection of configurations to be tested and the location of sensors for transition detection were based on CFD pre-test computations.

Then, as a complement to the analysis of experimental data, results from CFD calculations were used as inputs for boundary layer calculations. The use of both, experimental observation and transition prediction tools, lead to significant progress in understanding the physics governing the high-lift transition phenomena, and was one major outcome of the EUROLIFT program.

Then, this database has been used in order to validate recent developments on the elsA CFD solver on calculating the transition location during the computation. The transition is computed using a combination of different criteria, and is imposed when the first one, T.S. or crossflow, is activated. The first results obtained are very encouraging, particularly for the effect of the angle of attack variations. In that case, the computed transition location on the slat is very close to the measured one. Concerning the effect of the Reynolds number, the upward displacement of the transition is well simulated.

Based on these results, a first attempt to validate a so-called "adverse" Reynolds number effect on maximum lift will be investigated by ONERA in the EUROLIFT II project on a clean wing configuration at low speed, using these numerical tools. Meantime, improved transition prediction tools will be implemented in the elsA software, and validated on a realistic high-lift aircraft configuration at the end of this project.

\section{Acknowledgments}

The experimental results, the analysis and the prediction of the transition location have been obtained within the European research project EUROLIFT, under contract G4RD-CT-1999-00072, which was co-financed by the European Union within the $5^{\text {th }}$ Research Framework Program.

The results obtained for the CFD computations with transition computed and the effect of turbulence model have been supported by the French government agencies DGAC (Direction Générale de l'Aviation Civile) and SPAé (Services des Programmes Aéronautiques). 


\section{References}

[1] A.B. Haines and A.D. Young (Ed.). Scale Effects on Aircraft and Weapon Aerodynamics. AGARD-AG-32, July 1994.

[2] H.Hansen, P. Thiede, R. Rudnik, F. Moens and J. Quest. Overview about the European High Lift Research Programme EUROLIFT. AIAA 2004-767, 42 ${ }^{\text {nd }}$ AIAA Aerospace Sciences Meeting and Exhibit. Reno (Nevada), January 2004.

[3] R. Rudnik, P. Eliasson and J. Perraud. Evaluation of CFD Methods for Transport Aircraft High-Lift Systems. Presented as Paper 30 at the CEAS Aerospace Aerodynamics Conference, London (UK), June 1012, 2003. The Aeronautical Journal, February 2005, Pages 53-64, Paper n ${ }^{\circ} 2895$.

[4] P. Eliasson, F. Moens, H. Jakob, C. Newbold and H. Maseland. 3D High-Lift Computations. FOI Memo 784, GARTEUR TP-133, March 2004.

[5] W. Pfenninger. Flow Phenomena at the Leading Edge of a Swept Wing. Recent Developments in Boundary Layer Research, Part IV, AGARDograph 97, May 1965.

[6] A. Séraudie, J. Perraud and F. Moens. Transition Measurements and Analysis on a Swept Wing in High-Lift Configuration. ICAS 2002-197, $23^{\text {rd }}$ Congress of ICAS, Toronto 2002. Aerospace Science Technology Vol. $7, \mathrm{~N}^{\mathrm{o}} 8,2003$, pp 569-576.

[7] J. Perraud, A. Séraudie and F. Moens. Transition on a High-Lift Swept Wing in the European Project EUROLIFT. Presented as Paper 2003-3796 at the 21 ${ }^{\text {st }}$ AIAA Applied Aerodynamics Conference, Orlando (Florida) June 2003. Journal of Aircraft, Vol. 41, №5, pp 1183-1190, September-October 2004.

[8] M. Gazaix, A. Jollès and M. Lazareff. The elsA Object-Oriented Computational Tool for Industrial Applications. ICAS 2002-1.10.3.1, $23^{\text {rd }}$ Congress of ICAS, Toronto, September 2002.

[9] S. Ben Khelil, J.L. Gervois, G. Carrier, F. Moens, P. Viscat and Ch. François. Assessment of elsA Software through Civil Transport Aircraft Configurations. CEAS Aerospace Aerodynamics Research Conference, Cambridge, UK, June 2002.

[10] P.R. Spalart and S.R. Allmaras. A One-Equation Turbulence Model for Aerodynamic Flows. AIAA 920439, 1992.

[11] D.C. Wilcox. Reassessment of the Scale Determining Equation for Advanced Turbulence Models. AIAA Journal, Vol. 26, N ${ }^{0}$ 11, pp 1299-1310, 1988.

[12] B.R. Smith. A Near Wall Model for the k-l Two-Equation Turbulence Model. AIAA 94-2836, 1994.

[13] D. Arnal. Special Course on Stability and Transition of Laminar Flow. AGARD Special Course at the von Karman Institute, AGARD Report N ${ }^{0}$ 709, March 1984.

[14] C. Gleizes, J. Cousteix and J.L. Bonnet. Theoretical and Experimental Study of Low Reynolds Number Transitional Separation Bubbles. Proceedings of the Conference on Low Reynolds Number Airfoil Aerodynamics, UNDAS-C-77B123, June 1985.

[15] D. Arnal, M. Habiballah and E.Coustols. Laminar Instability Theory and Transition Criteria in Two or Three-Dimensional Flow. La Recherche Aérospatiale Nº1984-2, 1984.

[16] J. Quest, M.C. Wright, H. Hansen and G.G. Mesuro. First Measurements on an Airbus High-Lift Configuration at ETW up to flight Reynolds Number. AIAA 2002-0423. 